\title{
Minimisation of aminoglycoside toxicity in patients with cystic fibrosis
}

\author{
Paul J Wood, Lisa L Ioannides-Demos, Shu C Li, Trevor J Williams,
} Bernadette Hickey, W John Spicer, Robin E Hooper, Allan J McLean

\begin{abstract}
Background - There is evidence that administration of higher doses of aminoglycosides given less frequently improves the bactericidal effect and reduces the potential to cause side effects. To investigate this, a prospectively randomised open label therapeutic trial was undertaken in stratified groups of patients with cystic fibrosis to examine the efficacy and toxic potential of an aminoglycoside dosing regimen designed to generate high peak drug concentrations at 12 hourly intervals compared with conventional dosing at eight hourly intervals.
\end{abstract}

Methods - Patients in group A received tobramycin eight hourly using a dose aimed at generating a peak concentration of $10 \mathrm{mg} / 1$ with trough concentrations below $2 \mathrm{mg} / 1$, and those in group $B$ received the total daily dose required to achieve eight hourly target concentrations administered as two equal 12 hourly doses. Clinical outcomes measured and assessed included vestibular symptoms, hearing and renal function, length of hospital stay, readmission rate, and mortality.

Results - Twenty nine patients were recruited during a six month period, 20 to group $A$ and nine to group $B$. The average peak tobramycin level was higher in group B (12.5 (2.2) mg/l) than in group A $(7.9$ (1.9) $\mathrm{mg} / \mathrm{l})$, whilst the average trough level was higher in group $A(0.8(0.3) \mathrm{mg} / \mathrm{l})$ than in group $B(0.5(0.2) \mathrm{mg} / \mathrm{l})$. There was a difference in the number of ototoxic events between patients in group $A$ (seven of 18 , $38.9 \%$ ) and group $B$ (none of eight), but no difference was found in other outcome measures assessed.

Conclusions - These results suggest that 12 hourly high peak aminoglycoside dosing may be less toxic than equivalent eight hourly dosing, without any apparent difference in efficacy.

(Thorax 1996;51:369-373)

Keywords: aminoglycosides, cystic fibrosis, ototoxicity.

Correspondence to: Professor A J McLean, Department of Medicine and Geriatric Medicine, University of Sydney, Woden Valley Hospital, PO Box 11 , Woden, ACT 2606, Australia.

Received 26 May 1995 Returned to authors 22 August 1995 Revised version received 25 October 1995 Accepted for publication 22 November 1995 infections, yet their usefulness as antibiotics has been limited by their potential to cause ototoxicity and nephrotoxicity. ${ }^{1-6}$ There is evidence from both human and animal models that larger doses of aminoglycosides given less frequently reduce their potential to cause such side effects. ${ }^{4-17}$ The efficacy of larger less frequent aminoglycoside dosing regimens becomes a concern in patient groups whose clearance of the drug makes the interdose interval more critical, and these patient groups must be included in any rational analysis of this issue. Patients with cystic fibrosis represent such a group.

The primary pathogens implicated in the chronic lung infection associated with cystic fibrosis are Staphylococcus aureus, Streptococcus pneumoniae, Haemophilus influenzae, and Pseudomonas aeruginosa, the latter being responsible for chronic infection in $70-90 \%$ of all these patients. ${ }^{18-24} P$ aeruginosa undergoes phenotypic adaptation within the lungs of patients with cystic fibrosis, the most important being the emergence of mucoid strains. Higher concentrations of aminoglycosides are required for bactericidal activity against mucoid strains of $P$ aeruginos ${ }^{2425}$ consistent with observations that the best responses to aminoglycoside antibiotics have been seen in patients with cystic fibrosis with high plasma concentrations and correspondingly high sputum levels. ${ }^{1318222426-28}$ A larger volume of distribution coupled with an increased clearance of the drugs means that proportionally larger doses are also required to achieve adequate serum concentrations after dosing. ${ }^{1524272930}$

The aim of this study was to examine the efficacy and toxic potential of a dosing regimen of tobramycin which generates higher peak concentrations than those currently targeted in patients with cystic fibrosis. This was achieved by a randomised prospective comparison of two regimens of tobramycin in which the same total daily dose was administered at either eight or 12 hourly intervals.

\section{Methods}

PATIENTS

Patients with cystic fibrosis admitted to the Alfred Healthcare Group with an exacerbation of pulmonary infection, for which tobramycin was indicated according to microbiological criteria, were eligible for the study. Exclusion criteria were known allergy to aminoglycosides, renal impairment, clinically apparent hearing loss or vestibular disease, or involvement in the heart/lung transplant programme. Patients were stratified according to the severity and progression of their disease state using criteria applicable at the Royal Children's Hospital Australia to ensure that equal numbers of patients from each level of severity were represented in both groups. The three levels of 
stratification were severe (forced expiratory volume in one second $\left(\mathrm{FEV}_{1}\right)<50 \%$ predicted), moderate $\left(\mathrm{FEV}_{1} 50-70 \%\right.$ predicted) and mild $\left(\mathrm{FEV}_{1}>70 \%\right.$ predicted $)$, based on best results within the 12 months prior to the study, or the most recent result if more than 12 months. Randomisation took place before recruitment into the trial to accommodate potential involvement of patients transferred from the Royal Children's Hospital to the Alfred Healthcare Group. Patients were randomised by use of a random number generator. Informed consent was obtained from all patients and patient confidentiality was maintained for all patients entering the study. Patients who had already consented to the study were eligible to be enrolled on subsequent admissions. Those readmitted during the period of the study received the same dose of tobramycin as that received immediately before their previous discharge, thereby placing them in the same dosing group.

TOBRAMYCIN DOSAGE

Once stratified according to their disease state, the patients were randomised into two groups (A and B). Details of height, weight, age, and serum creatinine were recorded on all patients. This information was then entered into the aminoglycoside computer monitoring programme $e^{231}$ and appropriate doses were simulated. Initial doses were calculated by use of Bayesian forecasting whereby dosage predictions are based on population derived values rather than known blood concentrations of tobramycin. Once patients were entered into the trial and dosed, the resultant serum tobramycin concentrations were used to determine subsequent dosage recommendations using the patients' pharmacokinetic parameters. Patients in group A were recommended doses of tobramycin to be administered eight hourly to achieve target peak concentrations of $10 \mathrm{mg} / 1$ while maintaining trough concentrations below $2 \mathrm{mg} / \mathrm{l}$. Those in group B were recommended the total daily dose required to achieve peak concentrations of $10 \mathrm{mg} / 1$ if dosed eight hourly, but they were to receive the drug as two doses separated by 12 hourly intervals. Doses were reviewed twice weekly when tobramycin serum concentrations were available and dosing recommendations made using the computerised aminoglycoside pharmacokinetic programme to maintain levels within the target range. All tobramycin doses were administered by either intravenous bolus (over 1-2 minutes) or intravenous infusion in $50 \mathrm{ml}$ of compatible fluid over 30 minutes.

TOBRAMYCIN ASSAY

Serum concentrations of tobramycin were measured on all patients twice weekly according to standard policy of the unit. Serum "trough" samples were drawn immediately before the next dose and "peak" samples were drawn 30 minutes after completion of the infusion/bolus dose. In these patients $1 \mathrm{ml}$ of blood was obtained by finger prick. Serum tobramycin con- centrations were determined using fluorescent polarisation immunoassay (TDx, TDxFLx, Abbott Laboratories, North Chicago, Illinois, USA) by the Chemical Pathology Department.

ASSESSMENT OF CLINICAL OUTCOME

Data including patient weight, body temperature, serum creatinine, haematological results, tobramycin peak/trough plasma concentrations, sputum isolates and sensitivities, admission/discharge information, and concurrent medication were collected. Assessments made of clinical outcome included length of hospital stay, readmission rate, number of days between discharge and first readmission, response of measures of infection including sputum culture, antibiotic sensitivity data, and mortality. Patients were also required to complete a daily self-assessment form designed to determine the extent of patient well being with particular attention to symptoms suggestive of vestibular side effects.

\section{ASSESSMENT OF ADVERSE EFFECTS}

Nephrotoxicity was defined as an increase of $\geqslant 0.04 \mathrm{mmol} / 1$ in the serum creatinine concentration following treatment compared with the concentration before treatment, without any confounding factors. ${ }^{26}$ Serum creatinine levels were measured on admission and discharge. Because tobramycin almost exclusively undergoes renal elimination, the predose "trough" serum concentration can also indicate drug accumulation and therefore potential nephrotoxicity. ${ }^{15}$ Trough serum levels were monitored closely and, when indicated, additional serum creatinine levels were measured. Tobramycin clearance was calculated by the computer monitoring programme $\mathrm{e}^{231}$ on commencement and twice weekly during treatment.

Ototoxicity was defined as a loss of at least $15 \mathrm{~dB}$ in at least two adjacent frequencies, or $20 \mathrm{~dB}$ or more in any one frequency, in one or both ears, compared with evaluation before treatment. ${ }^{32}$ Audiometric tests were undertaken by the Department of Otoneurology to monitor hearing function in all patients before and after treatment with tobramycin, and in some instances during treatment. Hearing thresholds were determined by pure tone HughsonWestlake audiometry using Madsen OB822, Maico MA41 (250-8000 Hz, TDH39 headphones and calibrated to AS2586, 1983 standards), and Model AS10HF (8000-18 $000 \mathrm{~Hz}$, HV1A headphones) machines. The individual patient audiograms were then blindly assessed by the head of the Otoneurology Department for ototoxicity as defined by the study criteria. Vestibular side effects were monitored daily by patient self-assessment forms. Patients were required to note whether they had experienced any feelings of vertigo, dizziness, or lightheadedness during treatment. Provision was made for any suspected instances of vestibular toxicity to be referred immediately to the Department of Otoneurology for further assessment. The study protocol was approved by the AHG ethics committee. 
Table 1 Summary of mean (SD) results of patients studied

\begin{tabular}{|c|c|c|}
\hline & $\begin{array}{l}\text { Group } A \\
(8 \text { hourly }) \\
(n=20,16 \text { men })\end{array}$ & $\begin{array}{l}\text { Group B } \\
(12 \text { hourly }) \\
(n=9,6 \text { men })\end{array}$ \\
\hline Age (years) & $26 \cdot 7(9 \cdot 5)$ & $28 \cdot 7(8 \cdot 4)$ \\
\hline Patient weight $(\mathrm{kg})$ & $56 \cdot 8(8 \cdot 2)$ & $59 \cdot 5(13.9)$ \\
\hline Hospital stay (days) & $15 \cdot 4(9 \cdot 89)$ & $13 \cdot 0(5 \cdot 0)$ \\
\hline Time between discharge and first readmittance (days) & $63 \cdot 6(38 \cdot 1)$ & $75 \cdot 7(9 \cdot 2)$ \\
\hline Average dose of tobramycin (mg/patient/day) & $407 \cdot 5(56.9)$ & $406 \cdot 5(103 \cdot 7)$ \\
\hline Average dose of tobramycin $(\mathrm{mg} / \mathrm{kg} /$ day $)$ & $7 \cdot 2(0 \cdot 5)$ & $6 \cdot 8(0 \cdot 6)$ \\
\hline Mean tobramycin clearance ( $1 /$ hour) & $5 \cdot 0(0 \cdot 1)$ & $4 \cdot 3(0 \cdot 1)$ \\
\hline Trough aminoglycoside level (mg/l) & $0 \cdot 8(0 \cdot 3)$ & $0.5(0.2)^{*}$ \\
\hline Peak aminoglycoside level $(\mathrm{mg} / \mathrm{l})$ & $7.9(1.9)$ & $12 \cdot 5(2 \cdot 2)^{*}$ \\
\hline
\end{tabular}

${ }^{*} \mathrm{p}<0.001$
ASSESSMENT OF ADVERSE EVENTS

Neither group displayed nephrotoxicity as defined by the study criteria with serum creatinine concentrations before treatment (group A, 0.07 $(0.01) \mathrm{mmol} / 1$ (range $0.05-0.08 \mathrm{mmol} / \mathrm{l}), \mathrm{n}=$ 20; group $\mathrm{B}, 0.07 \quad(0.02) \mathrm{mmol} / \mathrm{l}$ (range $0 \cdot 04-0 \cdot 10 \mathrm{mmol} / \mathrm{l}), \mathrm{n}=8$ ) not differing from levels after treatment (group A, 0.06 $(0.01) \mathrm{mmol} / \mathrm{l}$ (range $0.05-0.08 \mathrm{mmol} / \mathrm{l}$ ), $\mathrm{n}=$ 15; group $\mathrm{B}, 0.07 \quad(0.02) \mathrm{mmol} / \mathrm{l}$ (range $0 \cdot 05-0 \cdot 11 \mathrm{mmol} / \mathrm{l}), \mathrm{n}=5$ ). No deaths were observed during the study. There was a significant association between ototoxicity and dosing schedule. Seven of the 18 monitored patients $(38.9 \%)$ displayed ototoxicity in group $\mathrm{A}$, whilst no cases of ototoxicity were observed in group B ( $<<0.05$, Fisher's exact test). The ototoxicity changes observed are summarised in table 2. Complete data were not available for some patients. Data were analysed using either Fisher's test or the unpaired Student's $t$ test. The unpaired Student's $t$ test was used when comparing two continuous variables for a significant difference. Fisher's exact test was used to compare two groups of discrete variables as the total number of observations ranged from eight to 50 . A level of $p<0.05$ was considered significant.

\section{Results}

STUDY POPULATION

During a six month period 49 patients were eligible according to the study criteria and were randomised accordingly. Of these patients, 29 (22 men) consented to participate in the trial. A random difference in refusals resulted in an imbalance in study groups. There was no significant difference between the two groups in terms of age and weight. All patients were treated with other intravenous antibiotics in addition to tobramycin - that is, antipseudomonal penicillins or third generation cephalosporins. There was no difference in the pattern of use of other antibiotics in the two groups that would influence outcome, and other management such as physiotherapy, diet supplements, and bronchodilators was the same in both groups.

The demographic features, admissions to hospitals, and tobramycin dosing data are summarised in table 1. Patients in group A had significantly higher measured trough levels of tobramycin than those in group $\mathbf{B}$ (group A, $0.8(0.3) \mathrm{mg} / 1$ (range $0.3-1.7 \mathrm{mg} / \mathrm{l})$; group $\mathrm{B}$, $0.5(0.2) \mathrm{mg} / \mathrm{l}$ (range $0.2-1.0 \mathrm{mg} / \mathrm{l}$ ). Patients in group $\mathrm{B}$ had significantly higher measured peak levels of tobramycin than those in group A (group A, 7.9 (1.9) $\mathrm{mg} / \mathrm{l}$ (range $4.0-13.7$ $\mathrm{mg} / \mathrm{l}$ ); group $\mathrm{B}, 12 \cdot 5(2 \cdot 2) \mathrm{mg} / \mathrm{l}$ (range $6 \cdot 6-16 \cdot 5$ $\mathrm{mg} / \mathrm{l})$ ). No other significant differences were seen. Thirteen of the 20 patients $(65.0 \%)$ in group A were readmitted during the course of the trial compared with three of the nine patients $(33 \cdot 3 \%)$ in group B.

SPUTUM CULTURES AND SENSITIVITIES

Sputum cultures and sensitivities, when performed on admission and discharge, did not show total eradication of offending pathogens $(P$ aeruginosa) in either group.

\section{Discussion}

The results of this randomised prospective comparative therapeutic trial of aminoglycoside dosing regimens hold immediate implications for the management of infection in patients with cystic fibrosis. The key result was that, under conditions of equivalent aggregate daily dosing, a 12 hourly dosing regimen produced apparently equivalent therapeutic outcomes with significantly reduced ototoxicity to an eight hourly regimen. The ototoxicity data potentially contribute to our understanding of the mechanisms involved in the production of damage to the cochlea.

The difference in toxicity reported reflects the measurement of a wide frequency range $(250-18000 \mathrm{~Hz})$ including, in particular, the high frequency range $(9000-18000 \mathrm{~Hz})$ where it is recognised that aminoglycoside ototoxicity first occurs in most $(71 \%)$ cases. $^{33}$ Paradoxically, full frequency assessment has only been undertaken in a fractional minority of the aminoglycoside literature reviewed by us and by others, ${ }^{33}$ and we could only identify two previous publications involving tobramycin. ${ }^{1321}$ We also adopted a rigorous definition of hearing change which is both sensitive and specific for toxicity; accordingly, these results, together with previous work, ${ }^{1321}$ represent important data for tobramycin. interval and mean, peak, and trough concentrations, we can only identify a minor difference in dose as a potential contributing factor to the difference in toxicity observed. The doses used in both groups (group A, 7.2

Table 2 Summary of ototoxicity changes in patients studied

\begin{tabular}{llll}
\hline $\begin{array}{l}\text { Patient } \\
\text { no. }\end{array}$ & Ear & $\begin{array}{l}\text { Frequency } \\
(\mathrm{kHz})\end{array}$ & $\begin{array}{l}\text { Hearing loss } \\
(\mathrm{dB})\end{array}$ \\
\hline 1 & Left & 10 & $\geqslant 20$ \\
2 & Left & 8 & $\geqslant 20$ \\
3 & Right & 9 & $\geqslant 20$ \\
4 & Left & 12 and 13 & $\geqslant 15$ \\
5 & Left & 16 & $\geqslant 20$ \\
6 & Right & 9 & $\geqslant 20$ \\
7 & Right & 1 & $\geqslant 20$ \\
\hline
\end{tabular}

Apart from the differences in interdose 
$(0.5) \mathrm{mg} / \mathrm{kg} /$ day and group B, $6.8(0.6) \mathrm{mg} / \mathrm{kg} /$ day) are, however, within the currently accepted ceiling for safe tobramycin dosing in patients with cystic fibrosis. ${ }^{731521}$ Accordingly we conclude that the dose delivery characteristics, rather than the doses themselves, have determined the difference in toxicity detected.

Peak concentrations were significantly higher in the 12 hourly dosing group, so peak concentrations alone can be dismissed as a causative influence in toxicity. This is consistent with other published series in which the toxic role of peak plasma concentrations has been assessed. ${ }^{67161734-38}$ The association between trough concentrations and ototoxicity has been minimally documented, but the currently acceptable trough level is $<2 \mathrm{mg} / 1 .{ }^{39}$ Accordingly, the results we observe indicate a need to reexamine the relationship between trough concentrations and ototoxicity as suggested by isolated examples published previously. ${ }^{4041}$

If animal data relating to cochlear/vestibular tissue binding and plasma/tissue concentration differentials are considered, the plasma concentration range at which inner ear binding is likely to saturate is $1 \cdot 8-10 \mathrm{mg} / 1 .{ }^{4243}$ If cochlear safety is related to the time during which tissues are not exposed to concentrations which saturate uptake, then the net time that each regimen is below such concentrations can be compared. Assuming a single compartment pharmacokinetic model ${ }^{44}$ and directly comparing the resultant drug plasma profiles for both groups, we calculate that the 12 hour regimen will result in longer times when the plasma concentration is below $2.5 \mathrm{mg} / 1$ than the eight hour regimen. Differences in outcome would therefore be expected between eight hourly and 12 hourly regimens if the plasma threshold concentration for the toxic effect was proposed to be at or below $2.5 \mathrm{mg} / \mathrm{l}$.

A simpler hypothesis would propose that the tissue uptake saturates rapidly at relatively low plasma concentrations. If a saturation point exists, it is the aminoglycoside concentration at which this occurs that must dictate the significant correlation between the drug plasma profiles in each group and the resulting ototoxicity. A balance must exist between the time of saturation, above which no further toxicity occurs, and the recovery time when drug concentrations fall below this saturation point. Multiple peak administration regimens would have a more pronounced influence on ototoxicity if the recovery time was the critical factor. Aminoglycoside dosing regimens that promote lower trough levels would potentially allow for longer recovery times. Our data would suggest that a 12 hourly interdose interval would allow such a recovery process to come to completion.

The disproportionate distribution of patients between the two groups does not allow for a definitive conclusion; however, the incidence of ototoxicity observed in this study is remarkably similar to that reported by other authors. ${ }^{621}$

Twelve hour dosing intervals appear to hold other advantages for patients. It was our experience that the trial patients in the 12 hourly arm adopted social patterns of greater mobility outside hospital and expressed a strong preference for the 12 hourly regimen. Such a regimen also has major economic advantages from the point of view of the use of clinical consumables and nursing time. ${ }^{4546}$

On the basis of our findings, the following alterations to cystic fibrosis dosing guidelines could be suggested subject to more extensive review of clinical efficacy. We propose a target post-distributional peak of $16.5 \mathrm{mg} / \mathrm{l}$, knowing it to be safe, ${ }^{17}$ and an interdose interval of 12 hours linked to such dosing exposure as this removes the apparent processes of ototoxicity. It may be possible to increase target peaks and interdose interval; however, any such change would require further prospective trials. It is therefore likely that, in patients with cystic fibrosis and high renal clearance, 12 hourly interdose intervals should be preferred to eight hour dosing intervals.

These studies were supported in part by the Alfred Hospital Whole Time Medical Specialists' Private Practice Trust Fund and the Alfred Healthcare Group Small Projects Grant.

We thank Ann Collins, Kathryn Godfrey, Mary Kalantzis, and Cheng-Wei Li from the Department of Otoneurology, Libby Francis from the Department of Respiratory Medicine, and Francis from the Department of Respiratory Medicine, and the nursing staff of Ward 5D for their technical advice and assistance.

This material has been presented in part at the 27th Annual Scientific Meeting of the Australasian Society of Clinical and Experimental Pharmacologists and Toxicologists, University of Queensland, Brisbane, Australia, 5-8 December 1993 and published in abstract form in Clin Exp Pharmacol Physiol 1993; Supplement 1:79.

1 Smith CR, Lipsky JJ, Laskin OL, Hellmann DB, Mellit ED, Longstreth J, et al. Double-blind comparison of the nephrotoxicity and auditory toxicity of gentamicin and tobramycin. N Engl f Med 1980;302:1106-9.

2 Sawyers CL, Moore RD, Lerner SA, Smith CR. A model for predicting nephrotoxicity in patients treated with aminoglycosides. F Infect Dis 1986;153:1062-8.

3 Kapusnik JE, Hackbarth CJ, Chambers HF, Carpenter T, Sande MA. Single, large, daily dosing versus intermittent dosing of tobramycin for treating experimental Pseudomonas pneumonia. $\mathcal{F}$ Infect Dis 1988;158:7-12.

4 Verpooten GA, Giuliano RA, Verbist L, Eestermans G, DeBroe ME. Once-daily dosing decreases renal accumulation of gentamicin and netilmicin. Clin Pharmaco Ther 1989;45:22-7.

5 Gilbert DN. Once-daily aminoglycoside therapy. Antimicrob Agents Chemother 1991;35:399-405.

6 Tulkens PM. Pharmacokinetic and toxicological evaluation of a once-daily regimen versus conventional schedules of netilmicin and amikacin. $f$ Antimicrob Chemother 1991;27: 49-61.

7 Powell SH, Thompson WL, Luthe MA, Stern RC, Grossniklaus DA, Bloxham DD, et al. Once-daily vs. continuous aminoglycoside dosing: efficacy and toxicity in animal and clinical studies of gentamicin, netilmicin and tobramycin. F Infect Dis 1983;147:918-32.

8 Tulkens PM. Mode of nephrotoxicity of aminoglycosides, and animal and human experience with a once daily regimen. In: Ueda Y, ed. International Symposium on Netilmicin. Professional Postgraduate Services International, 1987:10-11.

9 Henley III CM, Schacht J. Pharmacokinetics of aminoglycoside antibiotics in blood, inner-ear fluids and tissues and their relationship to ototoxicity. Audiology 1988;27: $137-46$.

10 Chan GLC. Alternative dosing strategy for aminoglycosides: impact on efficacy, nephrotoxicity, and ototoxicity. Drug Intell Clin Pharm 1989;23:788-93.

11 Garrison MW, Zaske DE, Rotschafer JC. Aminoglycosides: another perspective. Drug Intell Clin Pharm 1990;24:26771 .

12 Beaubien AR, Ormsby E, Bayne A, Carrier K, Crossfield G, Downes $M$, et al. Evidence that amikacin ototoxicity is related to total perilymph area under the concentrationtime curve regardless of concentration. Antimicrob Agents Chemother 1991;35:1070-4

13 Li SC, Bowes G, Ioannides-Demos LL, Spicer WJ, Hooper RE, Spelman DW, et al. Dosage adjustment and clinical outcomes of long-term use of high-dose tobramycin in adult cystic fibrosis patients. F Antimicrob Chemother 1991 ; 28:561-8.

14 Pechere JC, Craig WA, Meunier F. Once daily dosing of aminoglycoside: one step forward. F Antimicrob Chemother $1991 ; 27$ (Suppl C): 149-52. 
15 Lindsay CA, Bosso JA. Optimisation of antibiotic therapy in cystic fibrosis patients. Clin Pharmacokinet 1993;24: 496-506.

16 Prins JM, Buller HR, Kuiper EJ, Tange RA, Speelman P. Once versus thrice daily gentamicin in patients with serious infections. Lancet 1993;341:335-9.

17 Ioannides-Demos LL, Li SC, Bastone EB, Spelman DW, Hooper RE, Cousins VC, et al. Absence of toxicity in patients with malignant otitis externa following long-term treatment with high dose tobramycin. $\mathcal{f}$ Antimicrob Chemother 1994;34:267-74.

18 Parry MF, Neu HC. Tobramycin and ticarcillin therapy for exacerbations of pulmonary disease in patients with cystic fibrosis. F Infect Dis 1976;134(Suppl):194-7.

19 Hodson ME, Warne JO. Respiratory problems and their treatment. Br Med Bull 1992;48:931-48.

20 McCrae WM, Raeburn JA, Hanson EJ. Tobramycin therapy of infections due to Pseudomonas aeruginosa in patients with cystic fibrosis: effect of dosage and concentration of antibiotic in sputum. F Infect Dis 1976;134(Suppl): 191-3.

21 Pederson SS, Jensen T, Osterhammel D, Osterhammel P. Cumulative and acute toxicity of repeated high-dose P. Cumulative and acute toxicity of repeated high-dose
tobramycin treatment in cystic fibrosis. Antimicrob Agents tobramycin treatment in cystic

22 Govan JRW, Nelson JW. Microbiology of lung infection in cystic fibrosis. Br Med Bull 1992;48:912-30

$23 \mathrm{Li}$ SC, Ioannides-Demos LL, Spicer WJ, Spelman DW, Tong N, McLean AJ. Prospective audit of an aminoglycoside consultative service in a general teaching hospital. Med f Aust 1992;157:308-11.

24 Touw DJ, Vinks AATMM, Heijerman HGM, Bakker W. Validation of tobramycin monitoring in adolescent and adult patients with cystic fibrosis. Ther Drug Monit 1993; adult patien

25 Editorial. Pulmonary infection in cystic fibrosis - still a sticky problem. Lancet 1986;ii:1372-3.

26 Esau R, Hamilton D, Davidson AGF, Wong LTK. Toxicity of high dose tobramycin therapy in cystic fibrosis patients. Can $\mathcal{F}$ Hosp Pharm 1987;40:203-9.

27 Prandota J. Clinical pharmacology of antibiotics and other drugs in cystic fibrosis. Drugs 1988;35:542-78.

28 Ramsey BW, Dorkin HL, Eisenberg JD, Gibson RL Harwood IR, Kravitz RM, et al. Efficacy of aerosolized tobramycin in patients with cystic fibrosis. $N$ Engl $f \mathrm{Med}$ 1993;328:1740-6.

$29 \mathrm{Hsu} \mathrm{M,} \mathrm{Aguila} \mathrm{HA,} \mathrm{Schmidt} \mathrm{VL,} \mathrm{Munzenberger} \mathrm{PJ,}$ Kauffman RE, Polgar G. Individualization of tobramycin dosage in patients with cystic fibrosis. Pediatr Infect Dis 1984;3:526-9.

30 Kelly HB, Menendez R, Leland F, Murphy S. Pharmacokinetics of tobramycin in cystic fibrosis. $\mathcal{F}$ Pediatr 1982 ; 100:318-21.

$31 \mathrm{Li} \mathrm{SC}$, Ioannides-Demos LL, Harrison PM, Spicer WJ, Spelman DW, Tong N, et al. Case applications of a computer-aided aminoglycoside therapeutic monitoring technique. Aust f Hosp Pharm 1989;19:147-53.

32 Freeman $C D$, Quintiliani R, Nightingale $\mathrm{CH}$. Vancomycin therapeutic drug monitoring: is it necessary? Ann Pharmacother 1993;27:594-8.

33 Fausti SA, Henry JA, Schaffer HI, Olson DJ, Frey RH, McDonald WJ. High-frequency audiometric monitoring for early detection of aminoglycoside ototoxicity. $\mathcal{F}$ Infect Dis 1992;165:1026-32.

34 Rybak MJ, Boike SC, Levine DP, Erickson SR. Clinical use and toxicity of high-dose tobramycin in patients with pseudomonal endocarditis. If Antimicrob Chemother 1986; 17:115-20.

35 International Antimicrobial Therapy Cooperative Group of the European Organization for Research and Treatment of Cancer. Efficacy and toxicity of single daily doses of amikacin and ceftriaxone versus multiple daily doses of amikacin and ceftazidime for infection in patients with cancer and granulocytopenia. Ann Intern Med 1993;119: 584-93.

36 Gibson J, Johnson L, Snowdon L, Joshua D, Young G MacLeod C, et al. Single daily ceftriaxone and tobramycin in the empirical management of febrile neutropenic patients: a randomised trial. Int $f$ Hematol 1993;58:63-72.

37 TerBraak EW, DeVries PJ, Bouter KP, VanDerVegt SG Dorrestein GC, Nortier JW, et al. Once-daily dosing regimen for aminoglycoside plus $\beta$-lactam combination thergimen for aminoglycoside plus $\beta$-lactam combination therapy of serious bacterial infections: comparative trial with

38 Sturm AW. Netilmicin in the treatment of Gram-negative bacteremia: single daily versus multiple daily dosage. $\mathcal{f}$ Infect Dis 1989;159:931-7.

39 McCormack JP, Jewwesson PJ. A critical re-evaluation of the "therapeutic range" of aminoglycosides. Clin Infect Dis 1992;14:320-39.

40 Brushwood DB. Government liable for failure to monitor a patient's serum gentamicin concentration in an Army hospital. Am ₹ Hosp Pharm 1992;49:1748-50.

41 Halmagyi GM, Costantino MF, Curthoys IS, Wade S Gentamicin vestibulotoxicity. Otolaryngol Head Neck Surg 1994;111:571-4.

42 Tran Ba Huy P, Bernard P, Schacht J. Kinetics of gentamicin uptake and release in the rat. Comparison of inner ear tissues and fluids with other organs. F Clin Invest 1986; 77:1492-500.

43. Tran Ba Huy P, Deffrennes D. Aminoglycoside binding sites in the inner ears of guinea pigs. Antimicrob Agents Shemother 1988;32:467-72
Che in the

44 Pleasants RA, Williams DM, Waltner WE, Knowles MR. Influence of infusion method on serum tobramycin con-
centrations in adults with cystic fibrosis. Clin Pharmacol centrations in

45 Plumridge RJ. Cost comparison of intravenous antibiotic administration. Med $f$ A ust 1990;153:516-8.

46 Parker SE, Davey PG. Once-daily aminoglycoside administration in Gram-negative sepsis. Economic and practical aspects. Pharmacoeconomics 1995;7:393-402. 